\title{
KIT DE COMBATE A HOMOFOBIA DO MEC: A POLEMIZAÇÃO EM TORNO DOS RECURSOS AUDIOVISUAIS
}

\author{
Isaias Batista de Oliveira Júnior ${ }^{1}$
}

\section{RESUMO}

O discurso heterossexista inserido em nossa sociedade por meio de leis, religiões, políticas públicas curriculares, se tornou ainda mais evidente, em meados de 2011, diante da tentativa de lançamento do Kit de Combate a Homofobia,do Ministério da Educação e Cultura. A possibilidade de veiculação deste material nas escolas foi massificado na mídia, em redes sociais, entre legisladores/as, religiosos/as, sociedade civil, e Movimento LGBT propulsionando o nosso interesse pela temática. A partir daí assumimos o objetivo de analisar os recursos audiovisuais que integrariam o Kit de Combate a Homofobia do MEC delineado a partir do Projeto Escola Sem Homofobia. Diante do recuo do Estado na divulgação do material concluímos que, se o Governo Federal, devido às pressões, suspendeu à distribuição do Kit Anti-Homofobia, algumas pesquisas já realizadas sobre violência contra alunos/as Lésbicas, Gays, Bissexuais, Bigêneros, Travestis, Transexuais, Transgêneros, Queers, Questionadores/as, Intersexos, Indecisos/as, Assexuados/as e Aliados/as evidenciam que o ambiente escolar é altamente preconceituoso e excludente, o que, por si só, justificaria a produção de materiais didáticos, para além do Kit Gay, que pudessem colocar esse tema em discussão.

Palavras-Chave: Programa Brasil Sem Homofobia; Escola Sem Homofobia; Kit de Combate a Homofobia; Recursos Audiovisuais; Escola.

\section{ABSTRACT}

The heterosexist discourse inserted in our society through laws, religions, public curricular policies, became even more evident, in the middle of 2011, before the attempt to launch the Homophobia Combat Kit, of the Ministry of Education and Culture. The possibility of putting this material in schools was massified in the media, in social networks, among legislators, religious, civil society, and LGBT movement, propelling our interest in the subject. From that point on, we assumed the objective of analyzing the audiovisual resources that would be part Homophobia Combat Kit of the MEC outlined in the Project School Without Homophobia. In the face of the State's withdrawal in the dissemination of the material, we conclude that if the Federal Government, due to the pressures, suspended the distribution of the Anti-Homophobia Kit, some research has already been carried out on violence against Lesbian, Gay, Bisexual, Bigender, Transvestite, Transsexuals, Transgenders, Queers, Questioners, Intersex, Undecided, Asexual, and Allies show that the school environment is highly prejudiced and exclusive, which in itself would justify the production of didactic material, in addition to Of the Gay Kit, that could put this topic in discussion.

Keywords: Program Brazil Without Homophobia; School Without Homophobia; Kit Combat Homophobia; Audiovisual Resources; School. 


\section{Introdução}

Vale lembrar que em uma sociedade como a brasileira, constituída e estruturada pela diversidade, em que as diferenças são, com frequência, produzidas no curso das relações assimétricas, a promoção da cultura do reconhecimento da diversidade sexual pode representar mais do que um irrenunciável compromisso de ordem ética. No entanto, não surpreende o fato de que aqueles/as que aderem a "cultura de direitos" nem sempre estão dispostos/as a adotar um diálogo mais aprofundado, principalmente quando se refere à construção e promoção da cultura da diversidade sexual e o combate à LGBTQIAfobia ${ }^{2}$ empregada contra pessoas LGBTQIA -Lésbicas, Gays, Bissexuais, Bigêneros, Travestis, Transexuais, Transgêneros, Queers, Questionadores/as, Intersexos, Indecisos/as, Assexuados/as e Aliados/as (JUNQUEIRA, 2009, SCHULMAN, 2013).

No que se refere à diversidade sexual, as políticas educacionais comumente adotam como referência a matriz heteronormativa, desconsiderando

[...] a existência de um variado e dinâmico arsenal de normas, injunções disciplinadoras e disposições de controle voltadas a estabelecer e a impor padrões e imposições normalizantes no que concerne a corpo, gênero, sexualidade e a tudo o que lhes diz respeito, direta ou indiretamente. [...] Ela, inclusive, diz respeito a valores, mecanismos de exclusão, disposições e estruturas hierarquizantes, relações de poder, sistemas de crenças e de representação, padrões relacionais e identitários, todos eles voltados a naturalizar, impor, sancionar e legitimar uma única sequência sexo-gênerosexualidade, centrada na heterossexualidade (JUNQUEIRA, 2007, p.9).

Assim, o discurso heterossexista está inserido em nossa sociedade por meio de leis, religiões, políticas públicas curriculares, costumes, línguas etc. e qualquer postura que não comungue com essa prática, são consideradas atípicas, fato que se tornou evidente com a tentativa frustrada de lançamento do projeto conhecido como Kit de Combate e Prevenção a Homofobia, Kit anti-homofobia ou apelidado de "Kit gay" do MEC-Ministério da Educação e Cultura- que previa o tratamento da diversidade sexual e combate a homofobia (ROCHA FILHO, 2010).

A polêmica causada pela possibilidade de veiculação desse material nas escolas causou intensos debates na mídia, em redes sociais, entre legisladores/as, religiosos/as, sociedade civil e Movimento $\mathrm{LGBT}^{3}$, fato esse que, propulsionou nosso interesse pela área de pesquisa da Diversidade Sexual e da destituição de direitos mediante a negação de princípios elementares, como por exemplo, a discussão da temática no contexto escolar.

Justificada a escolha da temática adotamos como objetivo geral para este estudo descrever os recursos audiovisuais que integrariam o Kit de Combate a Homofobia do MEC e do Projeto Escola Sem Homofobia que compunha o Programa Brasil Sem Homofobia. A partir daí desdobram-se os objetivos específicos, quais sejam: delinear a dinâmica do Programa Brasil sem Homofobia e do seu subproduto o Projeto Escola sem Homofobia; analisar os recursos audiovisuais que comporiam o famigerado Kit Anti-homofobia do MEC e apontar os recursos audiovisuais como a contenda que levou a suspensão do Kit de Combate à Homofobia.

Para a discussão que segue colocamos em diálogo o Kit de Combate a Homofobia do MEC, originado como uma das medidas vinculadas à Educação, em cumprimento das ações previstas no Programa Brasil sem Homofobia e Projeto Escola Sem Homofobia, fazendo uma breve análise dos recursos audiovisuais que comporiam esse material, finalizando com alguns apontamentos que subsidiam a problemática. 


\section{Programa Brasil sem Homofobia}

A escola é vista como um local privilegiado de desenvolvimento de políticas públicas que visem à difusão da cultura do reconhecimento da(s) diferença(s), ao levar em consideração que tanto o homem quanto a mulher são produtos e produtores dos acontecimentos sócio-histórico-culturais e políticos, que influenciaram e influenciam o processo de formação identitária, no qual se inclui, de maneira pungente, a diversidade sexual (ALTMANN, 2003; JUNQUEIRA, 2009).

Afiançando esse entendimento por meio de uma articulação bem sucedida entre atores governamentais e não governamentais, que por aproximadamente seis meses se dedicaram a um trabalho intenso, porém, fundamental para a problematização, desestabilização e subversão da LGBTQIAfobia, o Programa Brasil sem Homofobia, a partir do ano de 2004, passou a fazer parte da agenda governamental (FERNANDES, 2011a).

Nesse sentido e considerando os efeitos danosos causados pela discriminação e preconceito relativos às sexualidades, o Governo Federal, na figura do Presidente Luiz Inácio Lula da Silva, por meio do Plano Plurianual de 2004 a 2007 definiu no âmbito do Programa Direitos Humanos Direito de Todos, a ação denominada Elaboração do Plano de Combate à Discriminação contra Homossexuais (BRASIL, 2004; BRANDÃO, SANTANA, 2011).

A Secretaria Especial de Direitos Humanos lança então o Programa Brasil sem Homofobia - Programa de Combate à Violência e à Discriminação contra pessoas LGBT e de Promoção à Cidadania de Homossexuais. Este programa possui o intuito de "[...] promover a cidadania e direitos humanos às [pessoas] lésbicas, gays, bissexuais, travestis [transexuais, transgêneros, queers, bigêneros, assexuados e intersexos] a partir da equiparação de direitos e do combate à violência e à discriminação homofóbicas" (BRANDÃO, SANTANA; 2011, p. 167).

Desenvolvido em um trabalho conjunto com atores governamentais e não governamentais, o Programa Brasil sem Homofobia procurou integrar as diversas esferas sociais no combate a LGBTQIAfobia por meio da articulação da política de promoção dos direitos de homossexuais; legislação e justiça; cooperação internacional; direito à segurança por meio do combate à violência e à impunidade; direito à educação, ao promover valores de respeito à paz e à não discriminação por opção sexual ${ }^{4}$; direito à saúde e consolidação de um atendimento e tratamentos igualitários; direito ao trabalho, garantindo uma política de acesso e de promoção da não discriminação por opção sexual; direito à cultura e construção de uma política de cultura de paz e valores de promoção da diversidade humana; política para a juventude; política para as mulheres e política contra o racismo e à homofobia (BRASIL, 2004).

Consideramos a relevância de todas as ações previstas pelo Programa Brasil sem Homofobia, porém, encerraremos nossas discussões acerca daquelas voltadas à educação, pois a escola é vista como um local onde o desmascaramento da violência simbólica poderia ser realizado com mais ênfase, já que ela se sustenta na sedução pela ignorância dos sentidos e nos significados reais de uma relação de desrespeito para com a(s) diferença(s) (ALTMANN, 2003).

No item V Direito à Educação: promovendo valores de respeito à paz e a não discriminação por opção sexual, o Programa Brasil sem Homofobia adotou como diretrizes orientar: 
I) os Sistemas de Ensino na implementação de ações que comprovem o respeito ao cidadão e à não-discriminação por orientação sexual; II) Fomentar e apoiar curso de formação inicial e continuada de professores na área da sexualidade; III) Formar equipes multidisciplinares para avaliação dos livros didáticos, de modo a eliminar aspectos discriminatórios por orientação sexual e a superação da homofobia; IV) Estimular a produção de materiais educativos (filmes, vídeos e publicações) sobre orientação sexual e superação da homofobia; V) Apoiar e divulgar a produção de materiais específicos para a formação de professores; VI) Divulgar as informações científicas sobre sexualidade humana; VII) Estimular a pesquisa e a difusão de conhecimentos que contribuam para o combate à violência e à discriminação de GLTB; VIII) Criar o Subcomitê sobre Educação em Direitos Humanos no Ministério da Educação, com a participação do movimento de homossexuais, para acompanhar e avaliar as diretrizes traçadas (BRASIL, 2004, p. 22-23, grifos nossos).

Em atendimento a essas diretrizes, o Governo decidiu adotar estratégias que efetivassem o cumprimento dessas demandas e surge, então, a iniciativa de estabelecimento do Projeto Escola sem Homofobia.

\section{O Projeto Escola sem Homofobia}

Constituído em 2009, mediante ação apoiada pelo MEC o projeto intitulado "Escola Sem Homofobia", cujo qual, fora elaborado e executado por uma coalizão de Organização Não Governamental - ONG - representativas do Movimento LGBT. A ação de execução do projeto envolveu uma grande quantidade de grupos filiados à $\mathrm{ABGLT}^{5}$ e visava interiorizar a agenda anti-homofobia na educação nos estados e municípios (INCLUSIVE, 2011; FERNANDES, 2011a).

Apresentando como princípios norteadores a contribuição para a efetivação do Programa Brasil sem Homofobia, por meio de ações que estabelecessem ambientes políticos e sociais favoráveis à garantia dos direitos humanos e da respeitabilidade das opções sexuais e identidade de gênero no âmbito escolar brasileiro.

Suas possíveis contribuições se traduziram em subsídios para a incorporação e a institucionalização de programas de enfrentamento à LGBTQIAfobia na escola, necessários na composição dos projetos político-pedagógicos das instituições de Ensino Médio do Brasil (BRANDÃO, SANTANA, 2011).

A execução do Projeto Escola Sem Homofobia ocorreu por meio da centralização do financiamento de ONG na agenda anti-homofobia no MEC após o segundo semestre de 2007, em uma ação coletiva que envolve pelo menos três grandes eixos: formação; levantamento de dados sobre a violência escolar contra alunos/as LGTQIA e elaboração e veiculação de materiais didáticos visando discutir a diversidade sexual no contexto escolar.

O primeiro eixo, sob a tutela e responsabilidade da Pathfinder ${ }^{6}$ do Brasil e da ABGLT, visou

[...] a formação de um coletivo gestor de políticas anti-homofobia nos estados e municípios que congregaria diferentes grupos sociais, prioritariamente pessoas que sejam sujeitas das populações LGBTTT (majoritariamente ativistas, mas também professores das redes de ensino público que sejam homossexuais ou trans), gestoras das secretarias estadual e municipal de educação, gestoras e outros profissionais 
envolvidos no programa Saúde e Prevenção nas Escolas (SPE), gestoras ou ativistas de direitos humanos que tenham algum tipo de aderência com a temática da homofobia e também acadêmicos. Nessa conformação caberia às entidades que compõem a coalizão executora do "Escola Sem Homofobia" formarem essa série de sujeitos para poderem gerenciar e/ou monitorar políticas anti-homofobia na educação no âmbito estadual ou municipal, sendo cada coletivo definido por estado da federação (FERNANDES, 2011a, p. 326).

O segundo eixo consistiu na realização de uma pesquisa qualitativa sobre "Homofobia nas Escolas", realizada pela ONG Reprolatina" - Soluções Inovadoras em Saúde Sexual e Reprodutiva, cujos resultados foram amplamente apresentados nos Estados e no Congresso Nacional (INCLUSIVE, 2011; FERNANDES, 2011a; ECOS, 2013a).

O terceiro eixo designado aos cuidados da $\operatorname{ECOS}^{8}$ residiu na elaboração e publicação de material didático a ser distribuído nas escolas públicas, com o apoio e financiamento do MEC. O material didático foi nomeado "Kit de Combate e Prevenção à Homofobia" (FERNANDES, 2011a).

A preparação do Kit de Combate à Homofobia demandou um investimento financeiro de aproximadamente 1,8 milhões em convênio que incluía, além da confecção de vídeos e cartilhas para professores/as, pesquisas, seminários e atividades de formação contínua para docentes (INCLUSIVE, 2011).

\section{O Kit de Combate à Homofobia: os recursos audiovisuais}

Além de conter uma série de medidas para combater o preconceito contra a opção sexual, também fazia parte da estrutura do Projeto Escola sem Homofobia a distribuição às escolas da rede pública de um chamado "Kit de Combate à Homofobia nas Escolas", também encontrado pelo nome de: "Kit Contra a Homofobia" ou "Kit Anti-homofobia" ou "Kit Gay", como veio a ser nomeado pelos opositores a sua distribuição (BRANDÃO, SANTANA, 2011; OLIVEIRA JÚNIOR, 2013).

Desenvolvido ao longo de dois anos, o kit seria composto por um conjunto de materiais didáticos incluindo: Boleshs (Boletins Escola sem Homofobia), cartaz de divulgação, carta de apresentação para gestores/as e educadores/as, Caderno (Escola sem Homofobia) e Recursos Audiovisuais: Medo de Quê? Boneca na Mochila, Torpedo, Encontrando Bianca e Probabilidade. Esses materiais seriam destinados aos/às profissionais da educação e distribuídos para seis mil escolas públicas de Ensino Médio, a partir do segundo semestre de 2011 (MELLO et al.,2012; BALESTERO, 2011).

Sabendo das distintas estratégias que seriam empregadas na abordagem da temática iremos nos ater ao debate acerca dos recursos audiovisuais. Acreditamos que eles poderiam ter sido empregados como a materialização ou a vivificação de uma ideia ou sentimento de respeito e convivência pacífica frente à diversidade sexual. Tal visão deve-se ao fato de que tais materiais poderiam comunicar algo devido a sua materialidade como portadora de um conteúdo que permitiria veicular uma ideia, uma intenção, uma mensagem moral ou política; ou seja, poderiam representar algo quando, articulando sua potencialidade expressiva e comunicativa, expressasse algo valorativo (PEREIRA, 2011).

Os recursos audiovisuais e os DVD que integrariam o kit viriam acompanhados de guias de discussão com sinopse, comentários e sugestões de atividades para o/a educador/a trabalhar os temas com a comunidade escolar.

O DVD "Boneca na mochila" na versão Libras, elaborado pela ECOS no ano de 1995, produzido pela agência Três Laranjas Comunicação com Roteiro de Reginaldo 
Bianco, descende de uma história baseada em fatos reais enfocando o diálogo entre uma mãe e um motorista de táxi que a conduz a caminho da escola, onde fora convocada a comparecer pelo fato de ter sido encontrada uma boneca na mochila de seu filho. Entre diálogos e notícias transmitidas pelo rádio do veículo, os temas homossexualidade e identidade de gênero vão sendo debatidos (BONECA, 2010).

O vídeo buscava promover a reflexão crítica sobre como as expectativas de gênero propagadas na sociedade influenciam a educação formal e informal de crianças, adolescentes e jovens por meio de situações que poderiam estar presentes em qualquer ambiente além da escola, mas principalmente nesse espaço. O vídeo estabelecia em alguns momentos manifestações homofóbicas contra as pessoas que são consideradas diferentes da norma imposta pelo processo de heternormatização (BONECA, 2010).

Em parceria com o Instituto Promundo ${ }^{10}$, Instituto PAPAI ${ }^{11}$, Pathifinder do Brasil, Reprolatina, The Global Alliance for LGBT Education - GALE ${ }^{12}$ e com apoio do Programa DST/AIDS do Ministério da Saúde, a ECOS produziu o vídeo "Medo de quê?"13. para integrar o Kit Anti-Homofobia do MEC.

Feito em formato de desenho animado e sem falas, traçava a trajetória de Marcelo, um personagem fictício que demonstrava seus conflitos por não corresponder às expectativas de sua família, sociedade e amigos, uma vez que seus desejos nem sempre supriam aquilo que as pessoas esperavam dele (MEDO, 2005).

A intenção do vídeo "Medo de quê?" para Silva (2007) era demonstrar como o sujeito se auto constitui, se reconhece e que tipo de relações estabelece com a regra, ou seja, como o indivíduo se percebe no campo de onde a "subjetivação" é produzida.

"Torpedo" de duas garotas que estudavam na mesma escola e que ao se relacionarem afetivamente em uma festa foram fotografadas e a notícia fora divulgada na web para toda a escola. Isso não as impediu de manifestar seus sentimentos e assumirem publicamente sua relação.

Furlani (2011a) identifica temáticas anteriores à questão da lesbianidade nesse material, como por exemplo, a invasão de privacidade, violência simbólica, coação coletiva e arrogância heteronormativa que poderiam ser discutidas com o vídeo.

"Encontrando Bianca"15 era uma animação composta por fotomontagem que retratava a história de José Ricardo, um aluno que tem a identidade de gênero feminina e portanto se apresentava como Bianca. A historieta evidenciava a descoberta de sua identidade travesti por meio de uma narrativa em primeira pessoa. Bianca revelava os dilemas que enfrentava corriqueiramente na escola como a dificuldade da comunidade escolar em reconhecê-la como Bianca, a recusa em chamá-la pelo nome social, o constrangimento e a inacessibilidade ao sanitário masculino e/ou feminino, além das situações de violência a qual era exposta no cotidiano escolar.

O recurso audiovisual "Probabilidade" 16 fora elaborado por meio de quadros de desenho e narrava a história de Leonardo, suas dúvidas e conflitos ao manter um relacionamento com Carla e sentir-se atraído por Rafael. Inicialmente, Leonardo sentia-se confuso, porém com o decorrer da história começou a se sentir aliviado ao concluir que ao manter uma identidade bissexual ele poderia gostar tanto de meninos, quanto de meninas.

O vídeo mostrava momentos de crises e reflexões na adolescência que giram em torno de situações de reconhecimento da sexualidade e alguns possíveis conflitos que jovens e adolescentes apresentam no momento de descoberta de uma bissexualidade.

Até esse momento, o vídeo vem com argumentos de probabilidades, que é o cunho do próprio título evidenciando a possibilidade das pessoas se relacionarem com ambos os gêneros como um fator positivo. A partir de então houve um equívoco na estratégia de inclusão do vídeo "Probabilidades". "[...] ele reforça o entendimento que as pessoas têm de 
relação, de vantagem, de quantidade de relacionamentos e não é essa a tônica que se vem desenvolvendo nos últimos anos [...]" (FURLANI, 2011c, s/p.).

Fernandes (2011c) comunga dessa teoria ao apontar que a reação contrária ao Kit como um todo se fundamentou nesse vídeo ao afirmar que um indivíduo bissexual tem $50 \%$ mais de chances de ficar com essa ou com aquela pessoa, ou seja, produz uma interpretação que a bissexualidade seria vantajosa.

Discussões à parte sobre qualidade do material ou de seu conteúdo, a intenção inicial da ECOS em parceria com a Pathifinder do Brasil, Reprolatina, a GALE e a ABGLT ao produzir os recursos audiovisuais, era primariamente estimular a cultura do respeito a(s) diferença(s) e a diversidade no cotidiano escolar.

Isso foi pensado mediante a implementação de distintas experiências estéticas que tais estratégias poderiam fornecer, de modo que os sujeitos da ação assumissem uma atitude estética, ou seja, uma posição, uma postura que constitua e configure uma percepção não intencional, mas como uma disposição contingente, uma abertura circunstancial frente a este debate (PEREIRA, 2011).

\section{Recursos Audiovisuais do Kit Anti-homofobia do MEC: o alvo da discórdia}

Tanto na política quanto na educação brasileira, quando se trata de direitos de uma parcela considerável de cidadãs e cidadãos que percorrem na contramão da ordem heteronormativa e buscam solidificar sua construção identitária dentro de uma matriz que não seja a via de regra, nada se dá de forma ágil e descomplicada. O/A inovador/a, o/a diferente, aquele/a que não obedece ao processo colonizador torna-se alvo constante de extremismo manifestado pelo não reconhecimento da(s) diferença(s) e desvalorização, principalmente no que se refere aos sujeitos LGBTQIA.

A comunicação inicial do processo de construção Kit de Combate e Prevenção a Homofobia ocorreu em meados de novembro de 2010, no seminário "Escola Sem Homofobia" realizado no Congresso Nacional em Brasília, no qual foram apresentados os primeiros resultados concretos do projeto, incluindo os dados da pesquisa qualitativa e os protótipos dos materiais didáticos que comporiam o Kit (FERNANDES, 2011a).

Além da função primária de estabelecer um diálogo da sociedade civil com o Estado no que se refere ao tratamento da diversidade sexual e combate à homofobia na escola, o Seminário, que tem semelhanças com o modelo de audiência pública, integrou uma "nova" estratégia do Congresso Nacional chamada "Comissão Participativa" (FERNANDES, 2011a).

No entanto, a apresentação inicial do Kit Anti-Homofobia gerou grande desconforto para a referida Comissão e Movimento LGBT causando desconfianças quanto à finalidade e intencionalidade do seu conteúdo. Ao mesmo tempo em que apresentava a seriedade do trabalho e como o mesmo se consolidou, é com indignação que foram ouvidas as declarações do ex-secretário do Ministério da Educação, André Lázaro, ao fazer piadas sobre o desenvolvimento do Kit de Combate à Homofobia que o Governo pretendia entregar nas escolas de Ensino Médio de todo o País (BRANDÃO, SANTANA, 2011).

A contestação em torno da fala do ex-secretário "[...] tem origem no momento em que discursava aos congressistas, representantes de entidades de apoio à confecção do material; autores dos vídeos e componentes da Comissão de Direitos Humanos da Minoria (CDHM)" (BRANDÃO, SANTANA, 2011, p. 172).

André Lázaro afirmara: “[...] Só para contar uma história à dificuldade num dos materiais didáticos, dos filmes, tinha um beijo na boca, e a gente ficou..., um beijo lésbico 
na boca..., e a gente ficou três meses discutindo até onde ia, até onde entrava a língua né [risos] [...]" (fala pessoal) ${ }^{17}$.

A discussão se tinha ou não o beijo lésbico no recurso audiovisual não é a tônica desse estudo, uma vez que muito se especula se o beijo existia e foi suprimido no vídeo, portando não se enfatizará aqui essa questão.

O discurso do então Secretário, André Lázaro instigou bancadas políticas e sociedade civil a agirem de forma contrária à elaboração do Kit Anti-Homofobia. A relação entre Estado e ONG tornou-se tensa nesse momento, principalmente com aquelas que lidam com temas de gênero, sexualidade, combate à LGBTQIAfobia e escola (BRANDÃO, SANTANA, 2011; FERNANDES, 2011a).

A recepção da proposta do Kit de Combate à Homofobia pelos setores conservadores (especialmente ligados ao fundamentalismo religioso), durante o Seminário do "Escola Sem Homofobia" na Câmara de Deputados do Congresso Nacional, foi permeada por polêmica, resistência e reação homofóbica (BRANDÃO, SANTANA, 2011; FERNANDES, 2011a).

A partir desse momento, datado no ano de 2010, câmaras legislativas se transformaram em cenários de repúdio ao projeto, atores/atrizes políticos recorriam à mídia frequentemente solicitando apoio da sociedade civil para conter a distribuição do material. Essa por sua vez distribuía pela rede mundial de computadores, incontáveis pedidos de suspensão do Kit Anti-Homofobia. Viu-se uma explosão discursiva na mídia impressa e televisiva que argumentava que o Governo Federal poderia incentivar práticas homoafetivas, ou "homossexualismo"18 como costumeiramente ouvíamos, em crianças e adolescentes ao apresentar a homossexualidade como uma prática respeitável (FERNANDES, 2011a; BRANDÃO, SANTANA, 2011).

A imprensa, as redes sociais, religiosos/as, legisladores/as, sociedade civil e mesmo quem não assistiu categoricamente afirmavam que o referido Kit ensinava as pessoas a serem homossexuais e que ele era um material que fazia apologia ao "homossexualismo" e que os vídeos eram destinados a crianças de seis, sete e oito anos de idade (BRANDÃO, SANTANA, 2011; FERNANDES, 2011a, FURLANI, 2011a).

Houve assim uma série de informações a respeito desse material e da campanha do MEC que são totalmente inverdades, difundidas e divulgadas por pessoas sem o mínimo de conhecimento (FURLANI, 2011a).

$\mathrm{Na}$ tentativa de minimizar os efeitos criados por essa atmosfera de inverdades, foi que associações de defesa dos direitos de LGBTQIA, organismos internacionais, pesquisadores/as e instituições manifestaram seu apoio à divulgação do material, considerado impróprio pela Presidenta Dilma Rousseff, mesmo após a contratação com verbas públicas de uma equipe técnica especializada para a confecção do Kit.

No entanto, essa rede de apoio que se formou em torno do Kit de Combate à Homofobia não foi suficiente para demover a ideia de suspensão do material da então Presidenta do Brasil Dilma Rousseff,que em 2011, diante de toda essa discussão e da pressão a que se viu exposta, mesmo sem ter acompanhado os vídeos, concordou que o material visual não possuía teor correto para ser apresentado à crianças e jovens e que o mesmo fazia propaganda de opção sexual (BRANDÃO, SANTANA, 2011).

Seu discurso pode ser acompanhado na mídia televisa ao se pronunciar em uma entrevista coletiva sobre os vídeos que comporiam o Kit de Combate e Prevenção a Homofobia.

[...] Eu não assisti aos vídeos todos. Há um pedaço que eu vi na televisão, passado por vocês, eu não concordo com eles. Agora, esta é uma questão que o governo vai revisar. Não haverá autorização para esse tipo de 
política, de defesa de "a", "b", "c" ou "d". Agora, nós lutamos contra a homofobia [...] (sic) (fala pessoal) ${ }^{19}$.

Dessa forma na quarta-feira, 25 de maio de 2011, na cidade de Brasília, sob determinação da Presidenta

[...] o Governo Federal decidiu suspender todas as produções de combate à homofobia que estavam sendo editadas pelo Ministério da Educação (MEC), mais especificamente, o material didático apelidado de "Kit Contra a Homofobia" do projeto Escola sem Homofobia, da Secretaria de Educação Continuada, Alfabetização e Diversidade do Ministério da Educação (GRESPAN, GOELLNER, 2011, p. 103).

Para a então Presidenta do Brasil, a função do Governo era apenas educar para que se evitassem agressões e desrespeitos às diferenças, não podendo interferir na vida particular dos sujeitos e nem propagar as opções sexuais.

[...] o Governo defende a educação e também a luta contra práticas homofóbicas. No entanto, o Governo não vai, não vai ser permitido a nenhum órgão do Governo fazer propaganda de opções sexuais. Nem de nenhuma forma nós não podemos interferir na vida privada das pessoas. Agora, o Governo pode sim fazer uma educação de que é necessário respeitar a diferença, que você não pode exercer práticas violentas contra aqueles que são diferentes de você, isso eu não concordo com o kit, porque eu não acho que ele faça defesa de práticas não homofóbicas (sic) (fala

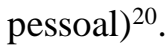

Esse foi o discurso final do Poder Executivo que pôs termo a uma série de debates e embates entre Movimento LGBT, as esferas de Poderes Legislativos e sociedade civil. Essas condutas demonstraram a atuação das tradições elitistas que persistem por meio da distinção hierárquica entre alta cultura e cultura de massa, entre cultura burguesa e cultura operária, entre cultura erudita e cultura popular, entre aqueles/as que regem a política e os/as que são regidos/as politicamente (COSTA, SILVEIRA, SOMMER, 2003).

Fernandes (2011c) defende que o kit gay não passou de um bode expiatório na delimitação de posições e da exposição ainda mais acirrada das posições conservadoras na sociedade o foco da polêmica envolve questões outras.

Para Bortolini (2012, s/p.)

As pessoas discutem muito a qualidade do kit, se os vídeos eram bons, se não eram. Em primeiro lugar esse veto não teve nenhuma relação com isso. Teve a ver com uma determinada conjuntura política na época e que, enfim, o kit foi usado como moeda de troca nesse jogo político [...] acho muito complicado porque vendo a Dilma, não só no veto ao kit, mas na fala dela depois reafirmando esse veto, dizendo que isso era uma questão de costumes, que não devia ser discutido na escola etc. [...] eu acho que as pessoas não têm a noção da magnitude disso na escola, da repercussão disso na escola [...] então se você tinha até aquele momento uma diretora que tava vendo situações de violência dentro da escola, que tava vendo um conflito gerado por essas questões dentro da escola, que tava [...] pensando se discutia ou não esse tema, depois de uma fala como essa, de um ato como esse do Governo Federal, essa professora que tava na dúvida tinha certeza que ela não tinha que fazer nada [...] isso provoca um mobilismo, 
um retrocesso, um medo de trabalhar essa questão, um medo de discutir essa questão muito forte. Inclusive dissemina essa desinformação de um material que ninguém viu, de um material que ninguém sabe quais são esses vídeos e que ninguém conhece e que acaba marcando outras questões, outros debates [...].

Corroborando com esse pensamento, Furlani (2011b) e Fernandes (2011b) alegaram que a então Presidenta demonstrou ser uma pessoa despreparada no sentido de conhecer as agendas dos movimentos sociais e muito facilmente foi manipulada. Acreditou, como muita gente, nas inverdades fundadas a respeito do Kit de Combate à Homofobia. A posição mais democrática que ela poderia ter adotado ao avaliar negativamente o material seria a de procurar o Comitê de Publicações do MEC, dialogar com o Ministério da Educação, com os/as autores/as do material e com o campo educacional, ao invés disso optou por uma declaração pública de veto sem conhecer o material.

Essa postura da Presidenta intensificou uma forma antidemocrática e antimeritocrática de avaliação de materiais didático-pedagógicos e trouxe novamente para o Estado brasileiro uma forma de avaliar uma produção intelectual e artística da sociedade civil de forma repressiva e centralizadora, uma vez que a partir desse episódio todo "[...] o material que se refira a "costumes" passará por uma consulta aos setores interessados da sociedade antes de serem publicados ou divulgados [...]" (BALESTERO, 2011, p. 10 -11).

Diante dessa panaceia pairam sucessivas indagações sobre a eficiência e efetividade de políticas públicas e estratégias educacionais de combate e prevenção à LGBTQIAfobia, por exemplo, como a escola lida com diversidade sexual e a manifestação do preconceito? Em quais discursos a escola se sustenta para discutir ou não a temática? Quais comportamentos comumente encontramos nos/as agentes educacionais como diretores/as escolares, pedagogas/os e docentes quando insistimos na necessidade da promoção da cultura do respeito? Se o Kit de Combate à Homofobia tivesse sua distribuição efetivada teria garantia de uso como estratégia pedagógica por educadores/as? Esses/as agentes teriam interesse em usá-lo? Acreditam ser um tema relevante a ser abordado e discutido em sala de aula?

Oliveira Jr (2013), em seu estudo ao entrevistar diretores/as, pedagogas e professoras do ensino médio acerca do Kit Gay, apontou que os/as educadores/as desconheciam o conteúdo do referido material, no entanto, parte deles/as discordava que a discussão devesse fazer parte da esfera escolar ou então apontavam para um não endosso do debate, por parte de outros/as educadores/as, caso o recurso tivesse chegado à escola.

Oliveira Jr (2013) concluiu então, que se o Kit Gay não tivesse sido suspenso antes mesmo da sua distribuição sofreria um processo de engavetamento escolar passando a compor os arquivos dos mobiliários escolares, mantendo o debate sobre a diversidade sexual sob o manto da invisibilidade.

\section{Conclusão}

Coadunando com os objetivos desse estudo, nos propomos a, brevemente, descrever a sistematização do Programa Brasil sem Homofobia definido pelo Plano Plurianual de 2004 a 2007 no âmbito do Programa Direitos Humanos Direito de Todos, cujo qual originou o Projeto Escola sem Homofobia, no ano de 2009, mediante coalizão de Organização Não Governamental - ONG - representativas do Movimento LGBT, que culminou com a proposição para o Ministério da Educação e Cultura e posterior elaboração do Kit de Combate à Homofobia. 
Composto por uma série de estratégias, como caderno, carta de apresentação, cartazes, Boleshs e recursos audiovisuais, o pano de fundo, das contendas que se levantaram contra o projeto se pautaram no conteúdo dos vídeos que integrariam o Kit.

Parte considerável da sociedade conservadora se mostrou avessa à divulgação dos materiais na rede pública de ensino médio. A própria escola se mostrou contrária à distribuição do material, mesmo sem conhecê-lo, como apontou Oliveira Jr (2013) em seus relatos. Diante desta panaceia o Estado, na figura da então Presidenta Dilma Rousseff, decidiu por fim ao projeto no ano de 2011.

Se diante do cenário aqui apresentando e sustentado na inadequabilidade dos recursos audiovisuais que comporiam o material, o Governo Federal, devido às pressões políticas e sociais, recuou em relação à distribuição do Kit Anti-Homofobia, algumas pesquisas já realizadas sobre violência contra alunos/as LGBTQIA, mostram que o ambiente escolar é altamente homofóbico e heterossexista o que, por si só, justificaria a necessidade da produção de materiais didáticos que pudessem colocar esses temas em discussão.

Outro fato que nos chama a atenção é que percorrido aproximadamente 04 anos após a suspensão do Kit de Combate e Prevenção a Homofobia, vimo-nos envoltos em discussões semelhantes, quando fundamentalistas religiosos que ocupam cargos legislativos e que foram avessos à divulgação do Kit Gay propagaram em 2015, nas redes sociais e mídia a distribuição de um novo material, como a reportagem publicada no portal R7 Notícias intitulada "Cartilha gay causa polêmica em escola no Rio" 21 . O material não foi produzido no Brasil, mas sim em Portugal, bem como não chegou às escolas tupiniquins, conforme esbravejavam.

Diante desse cenário de aversão as pessoas LGBTQIA, defendemos a ideia de que alguns recursos, como o Kit de Combate e Prevenção a Homofobia, poderiam minimamente produzir sentidos que caracterizariam determinadas experiências estéticas no seu público alvo, como um efeito do entrelaçamento, do arranjamento que esse sujeito poderia fazer com a temática da diversidade sexual, "de maneira rigorosa, ou seja, levadas em consideração as possibilidades de compreensão que a experiência torna viável” (PEREIRA, 2011, p. 119).

Sabemos da necessidade da implementação de recursos semelhantes ao Kitde Combate e Prevenção a Homofobia na escola, no que se refere à diversidade sexual, no entanto, defendemos que qualquer estratégia de intervenção deve se dar de forma conjunta e não unilateral fundamentada em um discurso homofóbico abarrotado de "achismos", pois as políticas educacionais impostas dessa maneira, deseducam e afetam a formação de todos/as envolvidos/as, o prejuízo é geral, porém, alguns/mas são chamados/as a pagar uma conta bem mais alta por não terem seus direitos assegurados, como fica evidente no relatório divulgado pelo Grupo Gay da Bahia (GGB) que aponta318 assassinatos de pessoas reconhecidamente homossexuais, em 2015, o que significa uma morte a cada 27 horas, sendo que desse grupo, $52 \%$ dos mortos eram gays, $37 \%$ travestis, $16 \%$ lésbicas e $10 \%$ bissexuais (GRUPO, 2015).

\section{Referências}

ABGLT. Associação Brasileira de Lésbicas, Gays, bissexuais Travestis e Transexuais. Carta de Princípios da Associação Brasileira de Gays, Lésbicas e Travestis. 2013. Disponível em <http://www.abglt.org.br/port/cartaprinc.php>. Acesso em: 22 mai. 2013.

ALTMANN, Helena. Orientação sexual em uma escola:recortes de corpo de gênero. Cadernos Pagu, Campinas SP, n. 21, 2003, p. 281-315. 
BALESTERO, Gabriela Soares. O direito à diversidade sexual no Brasil e os efeitos violentos do descaso do poder legislativo federal. Revista Espaço Acadêmico, v. 11, n. 123, Agosto, 2011, p. 05-16.

BONECA na mochila. Produção Estudos e Comunicação em Sexualidade e Reprodução Humana - ECOS. Direção de Reginaldo Bianco. Coordenação de Maria Helena Franco, Vera Simonetti. Intérprete de LIBRAS Fabiano Campos. Assessoria de LIBRAS de PauloVieira (surdo), Rafaella Sessenta. São Paulo: Jah Comunicação Audiovisual (reedição), 2. ed., 2010. 01 DVD (25 min), son., color.

BORTOLINI, A. Diversidade sexual na escola. Programa Sala de Notícias. Produção de Paula Fontes, Sara Oliveira e Jaqueline Souza. Rio de Janeiro: Canal Futura, 2012, parte 02. (Comunicação oral). Disponível em <http://www.youtube.com/watch?v=Hn-

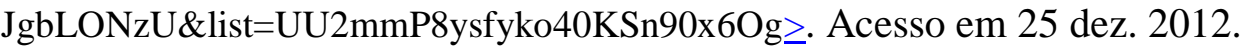

BORTOLINI, A. Diversidade sexual na escola. $1^{\text {a }}$ edição - Rio de Janeiro: Pró-Reitoria de Extensão/UFRJ, 2008.

BRANDÃO, Paula de Freitas. SANTANA, Tereza. O "kit gay": na saúde e na educação um kit de polêmicas. Caos. Revista Eletrônica de Ciências Sociais. n. 18, set. de 2011, p. 167176.

BRASIL. Conselho Nacional de Combate à Discriminação. Brasil Sem Homofobia: Programa de combate à violência e à discriminação contra GLTB e promoção da cidadania homossexual. Brasília: Ministério da Saúde, 2004.

COSTA, Marisa Vorraber. SILVEIRA, Rosa Hessel. SOMMER, Luis Henrique. Estudos culturais, educação e pedagogia. Revista Brasileira de Educação,

ECOS. Comunicação em Sexualidade. Projeto Escola sem Homofobia: contexto. 2013a. Disponível em <http://www.ecos.org.br/projetos/esh/esh.asp>. Acesso em: 05 jan. 2013.

ECOS. Comunicação em Sexualidade. $O$ que fazemos. 2013b. Disponível em <http://www.ecos.org.br/oqfazemos.asp>. Acesso em: 22 mai. 2013.

FERNANDES, Felipe Bruno Martins. A Agenda anti-homofobia na educação brasileira (2003-2010). 2011. 422 f. Tese de Doutorado. Universidade Federal de Santa Catarina. Florianópolis, 2011a.

FERNANDES, Felipe Bruno Martins. Estado, sexualidade e educação: a questão do kit antihomofobia. SC: Grupo de Diversidade Sexual da UDESC, 2011b. Disponível em <http://www.youtube.com/watch?v=_P3Rn0tfttg\&list=PL7309D62FFAB43733>. Acesso em: 23 dez. 2012.

FERNANDES, Felipe Bruno Martins. Estado, sexualidade e educação: a questão do kit antihomofobia. SC: Grupo de Diversidade Sexual da UDESC, 2011c. Disponível em <http://www.youtube.com/watch?v=ejtdZfUpW2M\&list=PL7309D62FFAB43733>. Acesso em: 23 dez. 2012. 
FURLANI, Jimena. Estado, sexualidade e educação: a questão do kit anti-homofobia. SC: Grupo de Diversidade Sexual da UDESC, 2011a. (Comunicação oral). Disponível em <http://www.youtube.com/watch?v=_P3Rn0tfttg>. Acesso em: 23 dez. 2012.

FURLANI, Jimena. Estado, sexualidade e educação: a questão do kit anti-homofobia. SC: Grupo de diversidade Sexual da UDESC, 2011b. (Comunicação oral). Disponível em <http://www.youtube.com/watch?v=DrfeN_pn9aw>. Acesso em: 23 dez. 2012.

FURLANI, Jimena. Estado, sexualidade e educação: a questão do kit anti-homofobia. SC: Grupo de diversidade Sexual da UDESC, 2011c. (Comunicação oral). Disponível em <http://www.youtube.com/watch?v=ejtdZfUpW2M>. Acesso em: 23 dez. 2012.

GALE. Global Alliance for LGBT Education. About us. 2013. Disponível em <http://www.lgbt-education.info/en/about_us>. Acesso em: 22 mai. 2013.

GRESPAN, Carla Lisboa. GOELLNER, Silvana Vilodre. "Querem, na escola, transformar seu filho de 6 a 8 anos em homossexual": Sexualidade, educação e a potência do discurso heteronormativo. R. FACED, Salvador, n.19, jan./jun.2011, p. 103-122.

GRUPO Gay da Bahia. Assassinato de LGBT no Brasil: Relatório 2015. Disponível em <https://grupogaydabahia.com.br/2016/01/28/assassinato-de-lgbt-no-brasil-relatorio2015/>. Acesso em: 06 mar. 2017.

INCLUSIVE. Nota Oficial sobre o Projeto Escola Sem Homofobia. 2011. Disponível em <http://www.inclusive.org.br/?p=18368>. Acesso em: 03 nov. 2012.

INSTITUTO Papai. Quem somos. Disponível em <http://www.institutopapai.blogspot.com.br/p/sobre-o-grupo.html>. Acesso em: 15 ago. 2013.

JUNQUEIRA, Rogério Diniz.O reconhecimento da diversidade sexual e a problematização da homofobia no contexto escolar. In: Seminário Corpo, Gênero e Sexualidade: discutindo práticas educativas. Anais. Rio Grande, RS: Ed. da FURG, 2007.

JUNQUEIRA, Rogério Diniz. "Aqui não temos gays nem lésbicas": estratégias discursivas de agentes públicos ante medidas de promoção do reconhecimento da diversidade sexual nas escolas. Bagoas. n. 04, p.171-190, 2009.

MEDO de quê? Produção Jah Comunicação Audiovisual. Direção e Criação de Reginaldo Bianco. Desenhos de Murilo Silva. Animação de Benjamin Bekeierman, Samuel Paiva. São Paulo: Jah Comunicação Audiovisual, 2005. 01 DVD (18 min), son, color.

OLIVEIRA JÚNIOR, Isaias Batista de. O/a diretor/a não viu, a pedagoga não ouviu e a professora não quer falar: discursos docentes sobre diversidade sexual, homofobia e "Kit Gay”. 2013. 260 f. Dissertação de Mestrado. Universidade estadual de Maringá. Maringá, 2013.

PATHFINDER do Brasil. Quem somos nós. 2013. Disponível em <http://www.pathfinderbrazil.org/site/PageServer>. Acesso em: 22 de mai. de 2013.

PEREIRA, Marcos Villela. Contribuições para entender a experiência estética. Revista Lusófona de Educação, 18, 2011, p. 111-123. 
PROMUNDO. Apresentação. Disponível em <http://www.promundo.org.br/opromundo/apresentacao/>. Acesso em: 15 ago. 2013.

PROMUNDO. Soluções Inovadoras em Saúde Sexual e Reprodutiva. Institucional. 2013. Disponível em <http://www.reprolatina.org.br/site/html/quem_somos/missao.asp>. Acesso em: 22 mai. 2013.

ROCHA FILHO, João Silva. O currículo escolar e as relações de heterossexismo e homofobia na educação básica. Fazendo Gênero. Diásporas, Diversidade, Deslocamentos. ago. 2010, p. 1-9.

SALA, Arianna. Construcciones identitarias em el contexto histórico-cultural: identidades lésbicas, histórias de vida y discursos sociales. 2007. 309 f. Tese (Doutorado). Universidad de Sevilla, Sevilla, 2007. Disponível em <http://fondosdigitales.us.es/media/thesis/1206/Y_TD_PS-312.pdf>. Acesso em: $12 \mathrm{fev}$. 2013.

SALA, Arianna. Opção x Orientação Sexual. Canal SAP. 2012. Disponível em $<\mathrm{http}: / /$ www.youtube.com/watch? $\mathrm{v}=\mathrm{nV}$ V2Vjn9Pf3I\&playnext=1\&list=PLiX7GB_A3TPhY TpQ7gLmCh5vcAdce3_V2\&feature=results_video>. Acesso em: 16 jan. 2013.

SILVA, Tomaz Tadeu da. Currículo e identidade social: territórios contestados. In: SILVA, Tomaz Tadeu da (Org). Alienígenas na sala de aula: uma introdução aos estudos culturais em educação. 5. ed. Petrópolis, RJ: Vozes, 1995, p. 190-207.

SCHULMAN, Michael. Assexuados, bichas \&cia: a nova geração gay nas universidades dos EUA. Tradução: Clara Alain. Texto originalmente publicado no jornal "The New York Times". Folha de S. Paulo. São Paulo, 17 de fev. de 2013.

SOUSA FILHO, Alípio de. A política do conceito: subversiva ou conservadora? - crítica à essencialização do conceito de orientação sexual. Bagoas, n. 04, 2009, p. 59-77.

${ }^{1}$ Doutor em Educação pela Universidade Estadual Júlio Mesquita Filho. Docente da Universidade Estadual do Paraná. Contato: jr_oliveira1979@ @otmail.com.

${ }^{2}$ Adotamos a expressão LGBTQIAfobia com a intençãode sublinhar que a intransigência social em relação à homossexualidade masculina (ideia implícita à noção de homofobia) não é da mesma ordem do desrespeito que atinge lésbicas (oprimidas por uma lesbofobia que, além de homofóbica, é machista e sexista), nem do repúdio que sistematicamente atinge travestis e transexuais, cujas existências ferem de morte os binarismos macho-fêmea, homem-mulher, o que as tornam vítimas preferenciais do terrorismo de gênero. Acredita-se que ao adotar um termo únicoevita-se o uso repetitivo das expressões Lesbofobia, Transfobia, Travestifobia, Tansgênerofobia, Gayfobia, Bifobia, Bigênerofobia, Queer fobia, Intersexofobia, Aliadofobia e Assexofobia, o que cansaria o/a leitor/a (SCHULMAN, 2013).

${ }^{3}$ Delimitamos para este artigo o uso da sigla LGBT quando nos referimos ao Movimento LGBT, Movimento de pessoas Lésbicas, Gays, Bissexuais, Travestis, Transgêneros e Transexuais e paralelamente faremos uso do termo LGBTQIAao nos referirmos aos sujeitos e manifestações da sexualidade, por compreender os possíveis desdobramentos das sexualidades abrigando além das pessoas Lésbicas, Gays, Bissexuais, Travestis, Transexuais, Transgêneros, os sujeitos Bigêneros, Queers, Questionadores, Intersexos, Indecisos, Assexuados e Aliados. (SCHULMAN, 2013).

${ }^{4}$ Embora o termo "opção sexual" soe com estranheza, para alguns estudiosos da área da sexualidade, visto a quase unanimidade do uso do termo orientação sexual, é possível encontrarmos autores como Sousa Filho 
(2009), Sala $(2007,2012)$ Junqueira $(2007,2009)$ e Oliveira $\operatorname{Jr}$ (2013) que defendem a ideia de que a manifestação da sexualidade é um processo em construção e vivida individualmente, portanto ela é cambiante e pode ocorrer por orientação ou por uma pluralidade de opções, escolhas, eleições e preferências que coincidem com determinados períodos da vivência do erotismo, da sensualidade e do desejo, não pela imposição de uma cultura nacional. Ao nos conscientizarmos que essa pluralidade nos caracteriza como sociedade e como indivíduos, somos impelidos/as a procurar novas formas de configurar um fator de enriquecimento e de desestabilização de sistemas de representações que hierarquizam termos e identidade(s) como verdadeiros, naturais e inevitáveis, estigmatizam identidades contrárias e subvertem outros conceitos

${ }^{5}$ A ABGLT - Associação Brasileira de Gays, Lésbicas e Travestis foi constituída em 31 de janeiro de 1995, na cidade de Curitiba, Estado do Paraná para lutar pelos direitos humanos e civis de pessoas LGBTQIA, cuja missão é unir esforços para a conquista de uma Sociedade Igualitária; promover a cidadania e contribuir para a construção de uma democracia sem quaisquer formas de discriminação afirmando a livre orientação sexual e identidades de gênero (ABGLT, 2013).

${ }^{6}$ A Pathfinder do Brasil é uma Organização Não Governamental brasileira com 26 anos de atuação no campo da saúde coletiva. Tem como compromisso precípuo a redução das vulnerabilidades que afetam a saúde e a felicidade de mulheres, homens, transgêneros, lésbicas e gays, sejam adolescentes, jovens ou adultos. Como estratégia institucional, apoia estratégias de empoderamento coletivo com potencialidade para desestabilizar as formas que resistem à instauração da dignidade nas relações sociais, seja no campo da saúde, seja na vida cotidiana. Neste sentido e com essa intenção, a Pathfinder do Brasil desenvolve parcerias locais diversas, promove a participação comunitária e fortalece as capacidades gerenciais e técnicas de indivíduos e organizações (PATHFINDER, 2013).

${ }^{7}$ A Reprolatinaé uma organização não governamental localizada no Brasil, mais especificamente no município de Campinas em São Paulo, que busca melhorar a saúde sexual e a saúde reprodutiva das populações menos favorecidas da América Latina. Possui como uma de suas metas a melhoria do acesso e da qualidade de atenção em saúde sexual e saúde reprodutiva e, para atingi-la, baseia suas ações em seis Marcos de Referência, que interligados norteiam e determinam suas atividades em cada ação: Sistema Único de Saúde (SUS); componente de participação; sexualidade - gênero - direitos sexuais - direitos reprodutivos; desenvolvimento organizacional e qualidade da atenção em planejamento familiar (REPROLATINA, 2013).

${ }^{8}$ A ECOS - Comunicação em Sexualidade é uma Organização NãoGovernamental com 20 anos de atuação consolidada na defesa dos direitos humanos, com ênfase nos direitos sexuais e direitos reprodutivos em especial de adolescentes e jovens, com a perspectiva de erradicar as discriminações relativas a gênero, orientação sexual, idade, raça/etnia, existência de deficiências, classe social. As atividades da ECOS estão estruturadas em cinco eixos: comunicação; projetos e pesquisas; educação continuada/capacitação; advocacy e consultoria (ECOS, 2013b).

9 Trecho da $1^{\mathrm{a}}$ edição sem a comunicação em LIBRAS (Língua Brasileira de Sinais formados a partir da combinação da forma e do movimento das mãos e do ponto no corpo ou no espaço onde esses sinais são feitos). Disponível em <http://www.youtube.com/watch?v=Hlm85X1_LFs>. Acesso em: 17 de dez. de 2011.

${ }^{10}$ O Instituto Promundo é uma organização brasileira com escritórios no Rio de Janeiro, no Brasil, em Washington, DC, nos Estados Unidos e em Kigali, em Ruanda, onde atuam como uma organização, compartilhando a mesma missão, objetivos, comunicação e ações de advocacy por meio da promoção masculinidades não-violentas e relações de gênero equitativas no Brasil e internacionalmente (PROMUNDO, 2013).

${ }^{11}$ Fundado em 1997, o Instituto PAPAI é uma ONG que atua com base em princípios feministas e defende a ideia de que uma sociedade justa é aquela em que homens e mulheres têm os mesmos direitos. Assim, consideramos fundamental o envolvimento dos homens nas questões relativas à sexualidade e à reprodução e uma ressignificação simbólica profunda sobre o masculino e as masculinidades em nossas práticas cotidianas, institucionais e culturais mais amplas (INSTITUTO, 2013) .

${ }^{12}$ A Global Alliance for LGBT Education - GALE - é uma comunidade de aprendizagem com foco em educação sobre sexualidade por meio da promoção da inclusão plena de pessoas que são discriminadas por causa de sua opção sexual, identidade sexual e/ou expressão de gênero. Apresenta como principais prioridades: desenvolvimento de projetos-pilotos nas escolas e de um coniunto de ferramentas para trabalhar com as escolas Revista HISTEDBR On-line, Campinas, $n^{\circ}$ 70, p. 319-334, dez. 2016-ISSN: 1676-2584 333 
por meio do monitoramento, promoção e implementação adequada do Direito à Educação por parte dos Estados, do desenvolvimento de um conjunto de ferramentas para ONGs para defender a educação da diversidade sexual, promoção e apoio a inclusão das questões LGBT na educação sexual em cooperação com a UNESCO da qual é parceira formal (GALE, 2013).

13 Disponível em duas partes <http://www.youtube.com/watch?v=S2qisJyKm0g> e<http://www.youtube.com/watch?v=2xOAyoER-Ts>. Acesso em: 06 de jun. de 2012

${ }^{14}$ Disponível em:<http://www.youtube.com/watch?v=TP_OjE_Fi2o>. Acesso em: 03 ago. 2012.

${ }^{15}$ Disponível em:<http://www.youtube.com/watch?v=fVGSrP-W3OM>. Acesso em: 03ago. 2012.

${ }^{16}$ Disponível em:<http://www.youtube.com/watch?v=2vfxsoFFXGc>. Acesso em: 03 ago. 2011.

${ }^{17}$ Disponível em: <http://www.youtube.com/watch?v=5DEFrCC9U_0 >. Acesso em: 27 jul. 2012.

${ }^{18} \mathrm{O}$ termo homossexualismo foi criado no final do século XIX por médicos, como a classificação de uma doença. Nas últimas décadas do século XX, os códigos de doenças (CID-X e DSM IV) retiraram a homossexualidade de suas classificações e, em 1990, a Organização Mundial de Saúde (OMS) aboliu a homossexualidade como doença de todas suas listas. Além disso, em 2001 o Conselho Federal de Psicologia do Brasil proibiu todos os profissionais da área de realizarem qualquer tratamento que vise uma possível "cura" da homossexualidade, visto que não é uma doença. O profissional que faça isso pode até mesmo ter seu registro cassado (BORTOLINI, 2008).

19 Em entrevista coletiva realizada no dia 26 de maio de 2011. Disponível em: <http://www.youtube.com/watch?v=ESftwb6gkyc>. Acesso em: 14 abr. 2012.

${ }^{20} I d$.

${ }^{21}$ Disponível em <http://noticias.r7.com/rio-de-janeiro/balanco-geral-rj/videos/cartilha-gay-causa-polemicaem-escola-no-rio-22102015>. Accesso em 02 mar. 2016.

Recebido: Março/2016.

Aprovado: Novembro/2016. 